\title{
KRITIK EKONOMI KONVENSIONAL DAN SOLUSI EKONOMI ISLAM
}

\section{Hendri Tanjung}

Universitas Ibn Khaldun Jl. KH. Soleh Iskandar Bogor

E-mail: hendri.tanjung@gmail.com

\begin{abstract}
Abstrak. Tujuan penelitian ini adalah untuk meninjau beberapa kritik terhadap ekonomi konvensional dalam beberapa aspek, yaitu, teori, budaya, etika, dan sistem. Pada saat yang sama, penelitian ini hendak mencari solusi bagi sebuah ekonomi yang sehat (Ekonomi Islam). Data yang digunakan dalam penelitian ini adalah Undang-Undang Nomor 3 Tahun 2006 tentang pengadilan agama, Undang-Undang Nomor 2 Tahun 1992 tentang asuransi, data dari Badan Zakat Nasional, dan data dari Bank Indonesia. Metode yang digunakan adalah metode kualitatif dengan menggunakan analisis deskriptif dan kajian literatur. Penelitian ini menyimpulkan bahwa ada banyak kritik terhadap ekonomi konvensional oleh para ekonom konvensional maupun para ahli ekonomi Islam. Untuk itu, harus ada solusi Islam di bidang ekonomi. Solusi ekonomi Islam dapat dilakukan dengan strategi integrasi pasar Islam dalam kegiatan ekonomi melalui zakat, waqaf, jaminan sosial Islam, sistem peradilan Islam dan lembaga keuangan Islam (Bank Islam, Takāful, dan Rahn).
\end{abstract}

Abstract. Purpose of this study is to review some critics to conventional economics in some aspects, i.e., theory, culture, ethics, and system. At the same time this study aims at searching some solutions for healthy economics (Islamic Economics). The data used in this study are Law No. 3 of 2006 on religious courts, Law No. 2 of 1992 on insurance, data from National Zakat Board, and data from Bank Indonesia. The methodology used is qualitative method using descriptive analysis and literature review. This study concludes that there have been many criticisms of the conventional economic by conventional economist as well as by experts of Islamic economics. To that end, there should be Islamic solution in the economic field. Solution of Islamic economics can be done by Islamic market integration strategy into economic activities through zakat, waqaf, Islamic social security, Islamic justice system and Islamic financial institutions ( Islamic Banks, Takāful, and Rahn).

Kata Kunci : kritik, ekonomi konvensional, ekonomi Islam. 


\section{PENDAHULUAN}

Ekonomi konvensional adalah ekonomi yang asing bagi ummat Islam khususnya Indonesia. Jauh sebelum penjajah datang, Indonesia sudah menerapkan sistem ekonomi bagi hasil. Misalnya saja dalam peternakan, dikenal istilah 'maroan', yang bermakna separuh hasil peternakannya untuk pemilik ternak dan separuh lagi untuk penggembalanya. Ada juga istilah 'mertelu' dalam pertanian yang artinya, sepertiga untuk pemilik lahan dan dua pertiga untuk penggarap.

Setelah penjajah datang ke Indonesia, mulailah dikenalkan sistem riba dalam sistem perbankan. Sampai sekarang, setelah kurang lebih 400 tahun, sistem riba ini terus berjalan. Padahal sistem riba ini sama sekali jauh dari nilai-nilai budaya masyarakat Indonesia, dan jauh dari nilai-nilai agama Islam.

Akibat penerapan riba yang demikian masif di seluruh sendi kehidupan manusia, maka krisis demi krisis dalam bidang ekonomi tidak dapat dihindarkan. Sebut saja krisis moneter Indonesia tahun 1997/1998 dan krisis global tahun 2008. Belum lagi krisis-krisis sebelumnya, yang dialami dunia, misalnya krisis besar (Great depression) tahun 1929 di Amerika.

Melihat pada kenyataan bahwa telah terjadi kegagalan ekonomi konvensional yang ditandai dengan krisis moneter dan ekonomi yang terjadi berulang-ulang, maka pertanyaan penting untuk dijawab adalah: pertama, apakah tidak ada kritikankritikan terhadap ekonomi konvensional, baik dari pakar ekonomi konvensional itu sendiri atau dari pakar ekonomi Islam? Kedua, apa solusi terhadap kritikan tersebut? Ketiga, bagaimana peluang dan kendala menerapkan solusi ekonomi Islam tersebut?

\section{TINJAUAN PUSTAKA}

Mahbubul Haq, ilmuwan pakistan yang kemudian mendirikan Mahbubul Haq Foundation, mengkritik ekonomi 
konvensional khususnya tentang kemiskinan. ${ }^{1}$ Penulis pernah berkunjung ke Mahbubul Haq Foundation di Islamabad dan mereka sangat intens dalam menyoroti Pembangunan Manusia.

Critovam Buarque mengkritik ekonomi konvensional dengan mengatakan ekonomi telah berakhir. Dalam The End of Economics, Ethics, and disorder of progress, Barque menyoroti perihal etika dalam ekonomi. ${ }^{2}$ Hal senada juga dipaparkan oleh Paul Ormerod dalam bukunya The Death of Economics, bahwa ilmu ekonomi konvensional telah mati. ${ }^{3}$ Jika ilmu ekonomi konvensional mati, maka diperlukan ekonomi baru sebagai pengganti.

Dari sisi moral, Amitai Etzioni melontarkan kritiknya terhadap ekonomi konvensional khususnya terkait dengan moralitas. ${ }^{4}$ Di sini, moral dalam ekonomi menempati posisi penting. Sedangkan dari sisi budaya, Fritjof Capra juga menyoroti ekonomi konvensional dalam kaitannya dengan budaya masyarakat. ${ }^{5}$ Artinya, mempelajari ekonomi tidak bisa dipisahkan dengan budaya.

Selanjutnya, Joseph Stiglizt-peraih hadiah nobel dalam bidang ekonomi pada tahun 2001- dalam bukunya Globalization and its discontents, memaparkan fakta-fakta kehancuran ekonomi lewat konsep globalisasi. ${ }^{6}$ Disusul kemudian Naomi Klein yang menceritakan bagaimana doktrin ekonomi kapitalis

${ }^{1}$ Mahbubul Haq, The poverty curtain: choices for the third world (New York: Columbia University Press, 1976).

${ }^{2}$ Critovam Buarque, The End of Economics, Ethics, and disorder of progress (London: Atlantic Highlands, N.J., USA : Zed Books, 1993). 1994).

${ }^{3}$ Paul Ormerod, The Death of Economics (New York: Faber and Faber,

${ }^{4}$ Amitai Etzioni, The Moral Dimension: Toward a new economics (New York: The Free Press, 1988).

${ }^{5}$ Fritjof Capra, The Turning Point, Science, Society, and The Rising Culture (New York: Simon and Schuster, 1982).

${ }^{6}$ Joseph Stiglizt, Globalization and its discontents (NewYork: WW. Norton \& Co., 2002) 
khususnya doktrin pasar bebas digunakan untuk menghancurkan ekonomi suatu bangsa. Kehancuran itu disebut Klein sebagai bencana kapitalisme. ${ }^{7}$

Hendri Tanjung dalam tulisannya di Jakarta Post yang berjudul The Failure of Economics Theories, menceritakan kesalahan mendasar dari teori ekonomi kapitalis, pada saat yang sama, memberi solusi pada aksiologi ekonomi Islam. ${ }^{8}$

Kritikan-kritikan tersebut dapat diklasifikasikan kedalam beberapa aspek: pertama, dari aspek moral, seperti kritikan CritoVan Barque (1993) dan Amitai Etziani (1988). Kedua, dari aspek sistem, seperti kritikan Mahbubul Haq (1970), Paul Emerald (1994), stiglitz (2002) dan Naomi Klein (2007). Ketiga, dari aspek budaya, seperti kritikan Fritjop Chapra (1999), dan keempat, dari aspek teori seperti kritikan Hendri tanjung (2009).

\section{METODE PENELITIAN}

Metodologi yang digunakan dalam tulisan ini adalah metode kualitatif dengan menggunakan analisis deskriptif dan literature review. Data yang digunakan adalah Undang-undang No. 3 tahun 2006 tentang peradilan agama, UU No. 2 tahun 1992 tentang perasuransian, Data Baznas, dan Data Bank Indonesia.

\section{HASIL DAN PEMBAHASAN}

Kritikan terhadap ekonomi barat sudah banyak dilontarkan oleh ahli-ahli ekonomi barat sendiri seperti: Schumpeter pada tahun 1940 yang mengatakan bahwa ekonomi memasuki masa krisis, Daniel Bell dan Irving Kristol tahun 1950-an dalam buku mereka The Crisis in Economic Theory, Gunnar Myrdal 1960-an yang pernah menjadi arsitek ekonomi pembangunan Pakistan

\footnotetext{
${ }^{7}$ Naomi Klein, The Shock Doctrine: The Rise of Disaster of Capitalism (London: Penguin Books Ltd., 2007).

${ }^{8}$ Hendri Tanjung, "The Failure of Economics Theories", Jakarta Post (04 Februari 2009)
} 
dengan bukunya Institusional Economics, Hyla Mint dalam bukunya Economic Theory and under developed countries.

Kritikan lain adalah kritikan Mahbubul Haq (1970), Amitai Etziani (1988), Crito-Van Barque (1993), Paul Emerald (1994), Fritjop Chapra (1999), Stiglitz (2004), Naomi Klein (2007). dan Hendri tanjung (2009).

Berkaca pada banyaknya kritikan itu, maka perlu dicari solusinya. Solusi yang pernah dilontarkan oleh pakar ekonomi sebelumnya seperti Umer Chapra melalui bukunya The Future of Economics: an Islamic Perspectives, adalah Ekonomi Islam. ${ }^{9}$

Hanya saja, yang patut dibahas lebih jauh adalah bagaimana menerapkan ekonomi Islam ke dalam ekonomi yang ada, atau strategi yang bagaimana yang dapat dilakukan untuk 'mengIslam-kan' ekonomi yang ada?

Sebelum menjawab itu, perlu dijelaskan, apa sebenarnya strategi itu. Strategi adalah pendekatan secara keseluruhan yang berkaitan dengan pelaksanaan gagasan, perencanaan, dan eksekusi sebuah aktivitas dalam kurun waktu tertentu. Di dalam strategi yang baik terdapat koordinasi tim kerja, memiliki tema, mengidentifikasi faktor pendukung yang sesuai dengan prinsipprinsip pelaksanaan gagasan secara rasional, efisien dalam pendanaan, dan memiliki taktik untuk mencapai tujuan secara efektif $^{10}$.

Menurut penulis, strategi yang merupakan pendekatan secara keseluruhan yang berkaitan dengan pelaksanaan ekonomi Islam, dapat dilakukan dengan melakukan integrasi ekonomi Islam ke dalam Ekonomi yang sudah ada.

Integrasi dapat dilakukan dengan melakukan integrasi nilainilai instrumental ekonomi Islam ke dalam ekonomi yang ada.

${ }^{9}$ Lihat: Umer Chapra, The future of Economics: an Islamic perspectives (t.tp.: Islamic Foudation, 2000)

${ }^{10} \mathrm{http}: / /$ id.wikipedia.org/wiki/Strategi (diakses 11 November 2014) 
Setidaknya ada 5 nilai-nilai instrumental Ekonomi Islam yang dapat diintegrasikan ke dalam ekonomi Indonesia, yaitu: zakat, wakaf, jaminan sosial, sistem peradilan dalam menyelesaikan sengketa ekonomi, dan Lembaga Keuangan Syariah (LKS).

\section{Zakat}

Zakat belum populer di masyarakat sebagai instrumen ekonomi Islam. Zakat dikenal sebagai penggugur kewajiban setelah berpuasa ramadhan (dhi. Zakat fitrah). Zakat harta (maal) belum memasyarakat di tengah-tengah ummat. Padahal, zakat banyak menyelesaikan persoalan ekonomi bangsa. Sebut saja di Pakistan, rumah sakit gratis, sekolah gratis, itu semua karena zakat.

Integrasi zakat ke dalam pajak, perlu perjuangan kita semua. Kita semua berharap agar zakat dapat dilakukan sebagai pengurang pajak, bukan sebagai pengurang objek pajak. Jika zakat dapat diberlakukan sebagai pengurang pajak, maka sumber penerimaan negara akan luar biasa dahsyatnya.

Pengumpulan zakat yang terdata oleh Badan Amil Zakat nasional (Baznas) pada tahun 2011 sebesar 1,3 triliun rupiah, meningkat menjadi 2,7 triliun rupiah pada tahun 2014. Dalam empat tahun, kenaikan pengumpulan zakat sebesar 130 persen. Hal ini sangat menggembirakan. Pada tahun 2015, dengan skenario optimis, pengumpulan zakat diproyeksikan di kisaran angka 3,62 triliun rupiah.

\section{Wakaf}

Integrasi wakaf ke dalam ekonomi Indonesia sudah dimulai dengan mendirikan Badan Wakaf Indonesia (BWI). Diharapkan BWI dapat mengelola harta wakaf yang sedemikian besar potensinya bagi kesejahteraan ummat.

Digambarkan bahwa harta wakaf di Indonesia cukup besar. Ada 268 ribu hektar tanah wakaf yang tersebar di 366 ribu lokasi. Potensi wakaf tunai minimal 26,4 trilyun rupiah pertahun 
(hitungan AM Saefuddin), dapat digunakan untuk membayar bunga hutang negara. Di pulau kecil Sisilia (Italia), ada 300 sekolah yang dibiayai dari harta wakaf.

Agar wakaf dapat optimal, maka ada 6 strategi yang ditawarkan: edukasi dan sosialisasi, optimalisasi pemanfaatan wakaf, membangun institusi pengelolaan wakaf yang amanah (misalnya, Social Investment Bank Limited di Bangladesh yang mengeluarkan cash waqaf certificate), reoptimalisasi pemanfaatan aset wakaf yang sudah dimanfaatkan, memanfaatkan wakaf untuk membangun sarana penunjang perdagangan, dan melakukan inovasi wakaf (misalnya, temporary wakaf).

\section{Jaminan Sosial}

Menurut penulis, ada hal yang urgen dilakukan oleh pemerintah terkait dengan jaminan sosial, yaitu urgensi pelaksanaan asuransi petani. Pemerintah harus mampu melindungi para petani dari gagal panen. Hal ini, selain memotivasi petani, juga sebagai strategi untuk mencapai swasembada pangan.

Asuransi petani ini dapat dilakukan oleh lembaga tersendiri, maupun oleh asuransi yang dimiliki oleh pemerintah (asuransi BUMN). Atau, asuransi ini dapat dilakukan oleh menteri sosial bekerjasama dengan menteri pertanian. Hal ini merupakan integrasi ekonomi Islam ke dalam kebijakan negara.

\section{Sistem Peradilan dalam menyelesaikan sengketa ekonomi}

Integrasi sistem ekonomi syariah ke dalam sistem hukum yang ada, dapat terjadi di dunia pengadilan. Sebagaimana diketahui, menurut UU No. 3 Tahun 2006 tentang pengadilan agama, dijelaskan dalam penjelasan pasal 49 bahwa yang dimaksud dengan ekonomi syariah adalah perbuatan atau kegiatan usaha yang dilaksanakan menurut prinsip syariah, antara lain meliputi: 
- Bank syariah

- Lembaga keuangan mikro syariah

- Asuransi syariah

- Reasuransi syariah

- Reksadana syariah

- Obligasi syariah dan surat berharga syariah

- Sekuritas syariah

- Pembiayaan syariah

- Pegadaian syariah

- Dana pensiun lembaga keuangan syariah

- Bisnis syariah

Sengketa yang melibatkan lembaga keuangan syariah diatas, diselesaikan di pengadilan agama.

Dalam UU No. 21 Tahun 2008 tentang perbankan syariah menyebutkan tentang penyelesaian sengketa (Bab IX) Pasal 55 menetapkan:

- Penyelesaian sengketa perbankan syariah dilakukan oleh pengadilan dalam lingkungan peradilan agama.

- Dalam hal para pihak telah memperjanjikan penyelesaian sengketa selain sebagaimana dimaksud pada ayat (1) penyelesaian sengketa dilakukan sesuai dengan isi akad.

- Penyelesaian sengketa sebagaimana dimaksud pada ayat (2) tidak boleh bertentangan dengan prinsip syariah.

\section{Lembaga Keuangan Syariah (LKS)}

Dalam upaya mengembangkan lembaga keuangan syariah, Majelis Ulama Indonesia (MUI) mempunyai andil yang cukup kuat. Sebagai komitmen memelihara nilai-nilai ekonomi lembaga keuangan syariah, MUI membentuk Dewan Syariah Nasional (DSN). Dalam perjuangan menggapai payung yuridis, peran DSN sangat besar. Sampai tahun 2014, DSN telah mengeluarkan 95 fatwa terkait keuangan syariah. 
Sebelum menguraikan kinerja pertumbuhan Bank syariah, asuransi syariah, dan pegadaian syariah, dijelaskan dulu kendala yang dihadapi dalam pertumbuhan LKS ini. Kendala pertama adalah kemampuan LKS untuk 'mengepakkan' sayapnya yang relatif masih kecil, dan kendala kedua, sikap pragmatisme masyarakat.

\section{- Perbankan Syariah}

Dalam operasionalnya, sistem perbankan syariah memungut dana masyarakat berupa: Giro wadiah, deposito mudharabah, dan tabungan mudharabah. Adapun produk penyaluran dana kepada masyarakat, dapat dilakukan dengan 6 hal: pembiayaan mudhorobah, murabahah, Bai' Bithsaman a'jil, qardhul Hasan, ijarah dan penyertaan musyarakah.

IFDR (2013) menempatkan perbankan syariah Indonesia menempati ranking urutan ke 9 dunia, setingkat dibawah Turki. Dengan jumlah bank syariah sebanyak 197 bank tahun 2014, maka ke depan, bank-bank syariah ini memiliki prospek yang cukup baik. Saat ini terdapat 11 Bank Umum syariah (BUS), 23 Unit usaha Syariah (UUS) dan 163 Bank Perkreditan Rakyat Syariah (BPRS).

Pertumbuhan rata-rata dalam 5 tahun terakhir, pertumbuhan pembiayaan 36\%, dana pihak ketiga 35\%, Asset $40 \%$, Deposito 62\%, dan pembiayaan Murabaha 60\%. Sementara itu, total pembiayaan yang sudah diberikan sebesar 187,7 triliun, dengan perincian 76,6 triliun pembiayaan konsumer, 75,7 triliun pembiayaan modal kerja, dan 35,4 triliun pembiayaan investasi. Sementara itu, total asset perbankan syariah adalah 250,13 triliun rupiah, per akhir 2014. Namun, yang perlu diperhatikan adalah pangsa pasar bank syariah yang masih dibawah $5 \%$.

Untuk tahun 2015, diproyeksikan dengan skenario optimis, pangsa pasar perbankan syariah akan mencapai $6 \%$. Hal ini dapat dicapai jika mengikuti rekomendasi Masyarakat Ekonomi Syariah 
(MES) terhadap perbankan syariah. Adapun rekomendasi MES tersebut adalah sebagai berikut:

- Berani menjadi bank spesifik, fokus produk \& segmen;

- Perkuat aliansi strategis dgn BPRS \& BMT;

- Perkuat SDM dan riset;

- Perkuat peran Dewan Syariah Nasional (DSN);

- Perkuat dukungan dan keberpihakan Pemerintah; dan

- Dinamisasi kurikulum pendidikan ekonomi dan keuangan bank syariah.

Pertumbuhan industri perbankan syariah, mengalami fluktuasi (turun-naik). Dijelaskan bahwa fluktuasi ini terjadi karena adanya persaingan bank (khususnya bank syariah dengan bank konvensional). Hal ini sudah diteliti oleh Abduh dan Sukmana $(2011)^{11}$ yang menyimpulkan bahwa pertumbuhan deposit perbankan syariah dipengaruhi oleh tingkat suku bunga (interest rate) dan pendapatan (income).

Menurut penulis, lembaga syariah wajib menerapkan manajemen syariah. Untuk itulah, penulis bersama-sama dengan guru penulis: Professor DR KH Didin Hafidhuddin, menulis buku "Manajemen Syariah dalam Praktek"12, dengan salah satu tujuannya agar lembaga keuangan syariah dapat menerapkan manajemen syariah dalam menjalankan bisnisnya.

Meskipun pertumbuhan rata-rata diatas 30\% yang cukup menggembirakan, tetapi yang menyedihkan adalah berpindahtangannya kepemilikan bank syariah Indonesia ke

\footnotetext{
${ }^{11}$ Muhammad Abduh dan Raditya Sukmana, "Deposit Behaviour inIndonesia Islamic Banking: Do Crisis and Fatwa Matter?" Paper disampaikan pada Forum Riset perbankan Syariah ke-4 di Universitas Padjadjaran Bandung, 15-16 Desember 2011.

${ }^{12}$ Buku ini diterbitkan oleh Gema Insani Press, Jakarta tahun 2003 dan telah diterjemahkan ke dalam bahasa Inggris dengan judul "Sharia Principles on management in Practice", terbit tahun 2006.
} 
pihak asing. Sehingga dipertanyakan, "Bagaimana performa manajemennya?" Ada optimisme untuk mengembalikan saham bank syariah tersebut ke anak bangsa sendiri.

Kontribusi perbankan syariah dalam pengembangan ekonomi cukup baik, ditandai dengan 70\% untuk UMKM dan 30\% non UMKM. Sehingga keberadaan bank syariah sangat besar perannya dalam meningkatkan ekonomi masyarakat, khususnya usaha kecil menengah. Keberadaan bank syariah juga menyerap tenaga kerja yang besar jumlahnya. Tahun 2009 saja terserap 15.000 SDM, belum lagi multiplier effectnya.

\section{- Asuransi Syariah}

Jika asuransi konvensional mengandung unsur-unsur Gharar, maisir, dan Riba, maka asuransi syariah bersih dari unsurunsur seperti itu. Dalil Asuransi syariah adalah Qs Yusuf,12: ayat 43-49. Ada 10 prinsip asuransi syariah, yaitu: prinsip tauhid, keadilan, tolong menolong, kerjasama, amanah, saling ridha, menghindari riba, menghindari maisīr, menghindari gharar dan menghindari risywah.

Dasar hukum asuransi syariah di Indonesia adalah UU No. 2 tahun 1992 tentang perasuransian. Perkembangan asuransi syariah cukup pesat, dimulai dari 1 perusahaan (1994) menjadi 48 (2014) termasuk asuransi jiwa syariah, asuransi umum syariah, Unit usaha syariah asuransi jiwa, asuransi umum, dan reasuransi. Untuk lebih jelasnya lihat tabel 1.

Contoh produk-produk yang ditawarkan adalah Takaful Falah, dengan pembagian $80 \%$ bagi hasil, takaful salam (investasi + proteksi kesehatan), takaful kendaraan bermotor, takaful safari, takaful anshar, Fulnadi (takaful dana pendidikan), takaful kecelakaan pribadi, takaful pengangkutan, takaful kebakaran, dan takaful family care. 
Tabel 1

Jumlah Asuransi Syariah Indonesia tahun 2014

\begin{tabular}{|c|c|c|}
\hline No. & Jenis & Jumlah \\
\hline 1 & Asuransi Jiwa Syariah & 3 \\
\hline 2 & Asuransi Umum Syariah & 2 \\
\hline 3 & Unit Usaha Syariah Asuransi Jiwa & 17 \\
\hline 4 & Unit Usaha Syariah Asuransi Umum & 23 \\
\hline \multirow[t]{2}{*}{5} & Unit Syariah Reasuransi & 3 \\
\hline & & Total \\
\hline
\end{tabular}

Sumber: diolah dari berbagai sumber

Diproyeksikan pertumbuhan asuransi syariah 2015 cukup baik. Dengan skenario optimis, pertumbuhan asuransi syariah akan mencapai lebih dari 20\%. Dengan skenario moderat mengalami pertumbuhan antara 15 hingga $20 \%$. Dengan skenario pesimis pertumbuhan asuransi syariah tahun 2015 dibawah $15 \%$.

Tahun 2015, asuransi syariah diproyeksi tumbuh diatas $20 \%$ karena beberapa alasan, antara lain:

- OJK akan mengacu pada aturan-aturan yang ditetapkan IFSB pengawasan industri syariah;

- Mulai 1 Januari 2015, industri asuransi syariah akan mulai mengimplementasikan prinsip dasar penyelenggaraan usaha asuransi dan reasuransi syariah;

- Meningkatnya jumlah masyarakat kelas menengah (penduduk yang belanja 2-20 US dollar/hari).

- Aturan OJK mengenai kewajiban spin-off asuransi syariah mendapatkan tanggapan yang positif dari berbagai pihak; 
- Pada Oktober 2013, OJK mencanangkan pengembangan asuransi mikro syariah; dan

- OJK dan BI sedang menyiapkan program layanan keuangan tanpa kantor (branchless banking) dalam rangka peningkatan financial inclusion.

\section{- Pegadaian syariah}

Pegadaian syariah mulai beroperasi di Indonesia tahun 2003. Sebelum didirikan, diadakan dulu studi banding ke Malaysia. Data tahun 2008, ada 3,7 \% pelanggan pegadaian syariah dari 19 juta total pelanggan pegadaian. Responsi masyarakat terhadap pegadaian syariah ini baik, diantaranya karena faktor cepat prosesnya, hanya 10-15 menit.

Adapun produk pegadaian syariah diantaranya: Rahn (9193\% dari harga taksir), ARRUM (AR Rahn untuk Usaha Mikro Kecil) dengan jaminan BPKB motor atau mobil, MULIA (Murabaha Logam Mulia dan Investasi Abadi), serta Pegadaian Amanah (Pembiayaan Kepemilikan kendaraan bermotor).

\section{PELUANG DAN KENDALA}

Perkembangan yang pesat dari LKS menunjukkan bahwa LKS di Indonesia memiliki peluang besar untuk dikembangkan. Hanya saja, dalam menangkap peluang tersebut, terdapat tantangan dan kendala yang tidak ringan seperti: terbatasnya SDM dan efisiensi yang rendah.

Kendala permodalan juga patut dicatat. Perlu modal besar untuk mencapai skala ekonomi. Kendala SDM meliputi jumlah, kualitas, paradigma dan spirit.

Bank syariah perlu meningkatkan kualitas sistem pengawasan. Menurut penulis, diperlukan Dewan pengawas Syariah (DPS) yang full time, seperti yang diterapkan di Islamic Bangladesh Bank Limited (IBBL), dimana dalam praktek 
hariannya, DPS mempunyai wewenang menghentikan pembiayaan yang tidak syar'i.

Prospek asuransi syariah dapat melebihi perbankan syariah. Begitu juga dengan prospek pegadaian syariah yang sangat positif, di luar dari apa yang diperkirakan.

Integrasi Lembaga keuangan yang diuraikan diatas ke dalam ekonomi Indonesia, terbukti menolong usaha kecil dan menengah, sekaligus menolong masyarakat bawah. Sampai saat ini, Bank Indonesia sangat giat mensosialisasikan perbankan syariah, diantaranya dengan mengadakan training of Trainers (TOT) dosen-dosen ekonomi Islam se- Indonesia, yang dilakukan setiap tahun. Untuk tahun 2013 saja, Bank Indonesia sudah menyelenggarakan empat kali TOT, yaitu di Banjarmasin bulan juni, di Ternate bulan September, dan Medan serta Jambi di bulan Oktober 2013.

\section{PENUTUP}

Ada tiga hal yang dapat disimpulkan dari kajian tulisan ini: pertama, sudah banyak kritikan terhadap ekonomi konvensional baik oleh pakar-pakar ekonomi konvensional maupun pakarpakar ekonomi Islam. Untuk itu, perlu dicari solusi Islam dalam bidang ekonomi. Kedua, solusi ekonomi Islam dapat dilakukan dengan strategi melakukan integrasi pasar syariah ke dalam kegiatan ekonomi melalui zakat, wakaf, jaminan sosial, sistem peradilan dan lembaga keuangan syariah. Ketiga, peluang ekonomi syariah ke depan sangat baik. Sementara itu, tantangan dan kendala yang dihadapi juga tidak ringan seperti: terbatasnya SDM, efisiensi yang rendah dan kendala permodalan.

Untuk itu, ada beberapa yang perlu dilakukan: Pertama, mengintegrasikan pajak dengan zakat melalui penetapan undangundang zakat sebagai pengurang pajak. Kedua, melakukan edukasi dan sosialisasi kepada masyarakat untuk menggalakkan waqaf. Ketifa, dalam hal jaminan sosial, sangat urgen dilakukan 
pelaksanaan asuransi petani oleh pemerintah. Hal ini merupakan integrasi ekonomi Islam ke dalam kebijakan negara. Keempat, untuk mengembangkan Lembaga keuangan Syariah seperti perbankan syariah, asuransi syariah, pegadaian syariah, diperlukan pengembangan SDM yang berkelanjutan. Kelima, regulator dalam hal ini bank Indonesia dan otoritas jasa keuangan (OJK) harus berupaya untuk terus menerus mengembangkan kualitas lembaga-lembaga keuangan syariah ini.

\section{DAFTAR PUSTAKA}

Abduh, Muhammad dan Raditya Sukmana, "Deposit Behaviour inIndonesia Islamic Banking: Do Crisis and Fatwa Matter?" Paper disampaikan pada Forum Riset perbankan Syariah ke4 di Universitas Padjadjaran Bandung, 15-16 Desember 2011.

Buarque, Critovam, The End of Economics, Ethics, and Disorder of Progress, London: Atlantic Highlands, N.J., USA : Zed Books, 1993).

Capra, Fritjof, The Turning Point, Science, Society, and The Rising Culture, New York: Simon and Schuster, 1982.

Etzioni, Amitai, The Moral Dimension: Toward a New Economics New York: The Free Press, 1988.

Haq, Mahbubul, The poverty curtain: choices for the third world, New York: Columbia University Press, 1976.

http://id.wikipedia.org/wiki/Strategi, diakses 11 November 2014

Klein, Naomi, The Shock Doctrine: The Rise of Disaster of Capitalism, London: Penguin Books Ltd., 2007.

Ormerod, Paul, The Death of Economics, New York: Faber and Faber, 1994.

Stiglizt, Joseph, Globalization and its discontents, NewYork: WW. Norton \& Co., 2002. 
Vol. 11, No. 2, Desember 2014: 277-292

Tanjung, Hendri, "The Failure of Economics Theories", Jakarta Post (04 Februari 2009).

Umer Chapra, The future of Economics: an Islamic perspectives, t.tp.: Islamic Foudation, 2000. 